\title{
África y la dinámica del coronavirus
}

\section{Ana María Sánchez ${ }^{1}$}

\section{Contribución en la Sección Debates Internacional}

Resumen: El continente africano cuenta con 54 países, territorios dependientes y distintos territorios integrados en Estados no africanos. Su población es mayor a los 1.000 millones de personas y en ese contexto, existe consenso acerca de la necesidad de mejora de la estructura de salud en el continente, que ha enfrentado a lo largo de los años, distintos desafíos (VIH-SIDA, enfermedades respiratorias de vías bajas, diarreas, malaria, tuberculosis, meningitis, sarampión, dengue, hepatitis $B$, etc.). Por otro lado, en diciembre de 2019, se inició en China, un brote de coronavirus (COVID-19), que sería declarado como pandemia, en marzo de 2020, cuyo alcance se extiende a más de 180 países, superando los 370.000 casos en todo el mundo, que ha llegado también al continente africano, reportándose casos en Angola, Argelia, Benín, Burkina Faso, Cabo Verde, Camerún, Congo, Costa de Marfil, Chad, Eritrea, el Reino de Eswatini, Egipto, Etiopía, Gabón, Gambia, Ghana, Guinea, Guinea Ecuatorial, Kenia, república Democrática de Congo, Madagascar, Mauricio, Mauritania, Mozanbique, Namibia, Níger, Nigeria, República Centroafricana, Tanzania, Ruanda, Senegal, Seychelles, Sudáfrica, Sudán, Togo, Túnez, Uganda, Zambia y Zimbabwe. Atendiendo a lo señalado, este trabajo revisa de manera somera la situación del continente africano en lo que hace a la pandemia y las dinámicas políticas generales frente a la situación y en el ámbito internacional, a través de la consulta de documentos, textos académicos y noticias periódicas.

\section{Introducción}

En el marco de la pandemia de coronavirus (COVID-19), iniciada en China, en diciembre de 2019 y declarada pandemia por la Organización Mundial de la Salud, en marzo de 2020, esta nota procura revisar someramente la situación del continente africano en cuanto a la pandemia y las dinámicas políticas generales frente a la situación y en el ámbito internacional.

\footnotetext{
1 Docente-investigadora; Coordinadora del Nodo de Estudios sobre Asia y África, del Centro de Estudios y de Gestión en Redes Académicas (CEGRA), de la Universidad Nacional de Río Cuarto (Córdoba, República Argentina) y actual Coordinadora Nacional de la Asociación Latinoamericana de Estudios de Asia y África/ALADAA, Sección Argentina. Correo electrónico: anasanchezprof@hotmail.com
} 
Para esta tarea, se utilizan fuentes documentales, textos académicos y noticias periódicas relacionados a la temática.

\section{África y la difusión del virus}

El continente africano cuenta con 54 países y en el contexto de la pandemia, cabe señalar que los casos positivos de coronavirus aumentaron a 1.365 casos (al 24 de marzo/ WHO, 2020), con por lo menos 40 de esos países, ya afectados (Mednick y Anna, 2020), aunque es importante resaltar que África es hasta el momento el continente menos afectado.

Angola anunció sus primeros 2 casos y cerró sus fronteras aéreas, terrestres y marítimas (WHO, 2020). Mientras el Banco de Fomento del país (BFA) dispuso varios millones de dólares para enfrentar la pandemia, la Ministra de Salud, Sílvia Lutucuta, anunció que el país contará con la ayuda de médicos cubanos, al tiempo que está en consulta diplomática con otros países como China y Brasil, por el mismo tema (ANGOP, 2020).

Argelia cuenta con 231 casos, 17 muertos y 65 recuperados (WHO, 2020) y autorizó el protocolo usualmente utilizado para tratar malaria, para ser aplicado a pacientes con coronavirus, atendiendo a lo señalado por un reciente estudio de origen francés (Xinhua, 2020).

Benín reportó 5 casos y Botswana, aún sin casos reportados, suspendió los viajes internacionales de todos los empleados del gobierno. Burkina Faso, un estado sumamente frágil, con una creciente crisis humanitaria causada por ataques vinculados a extremistas islámicos, con 99 casos, tiene ya 3 muertos, habiendo cerrado sus dos aeropuertos internacionales durante dos semanas, con excepción de los militares y cualquier carga, que deba ser transportada (WHO, 2020).

Cabo Verde reportó 3 casos positivos y 1 muerte, la de un turista británico (Malaymail, 2020), mientras Camerún cuenta ya con 72 casos positivos (WHO, 2020). Congo reportó 4 casos; Costa de Marfil fue el último en anunciar que estaba cerrando sus fronteras y cuenta ya con 25 casos. Chad cuenta con 3 casos positivos; Eritrea con 1 y el reino de Eswatini (o Suazilandia) con 4 (WHO, 2020).

Egipto, la nación más poblada del mundo árabe y que cuenta con 366 casos positivos y 19 muertes, impuso un toque de queda nocturno en todo el país durante dos semanas, en afán de contener la propagación del coronavirus (Wahba y Magdy, 2020).

En Etiopía, se reportaron hasta ahora 11 casos; en Gabón, 6 casos y 1 muerto; en Gambia 1 caso; en Ghana, 27 casos y 2 muertos; en Guinea 4 casos y en Guinea Ecuatorial, 6 (WHO, 2020). 
En Kenia, que tiene 16 casos, los funcionarios de salud avanzan en la desinfección de mercados que suelen estar abarrotados, en Nairobi, la ciudad capital del país, mientras Liberia presenta sólo 3 casos hasta el momento y la República Democrática de Congo, 36 y 2 muertos (WHO, 2020).

Madagascar tiene 13 casos; Mauricio 36; Mauritania 2; Mozanbique 1; Namibia 3 y Níger 2 casos. En Nigeria, que hace apenas unas pocas semanas anunció el primer caso de coronavirus en África subsahariana, el de un hombre, que había viajado desde Italia y tiene en la actualidad 25 casos positivos, se anunció ya la primera muerte (otro hombre, de 67 años, que venía de viajar al Reino Unido y tenía una condición médica previa) (RFI, 2020; WHO, 2020).

La República Centroafricana reportó 4 casos; la República Unida de Tanzania 12; Ruanda 36; Senegal 79 casos y 8 recuperados y Seychelles, 7 casos (WHO, 2020).

En lo que respecta a Sudáfrica, si bien el pico inicial comprendió a personas con más recursos, que habían estado viajando, si el virus no es contenido y la transmisión comunitaria se intensifica, podría constituir, como bien puede imaginarse, un alto riesgo para los grupos sociales más vulnerables. Mientras tanto, la circulación del virus aumenta rápidamente (el número de casos subió de 150 -19 de marzo- a 557 -24 de marzo-, ubicándolo como el país con más casos en el continente (WHO, 2020). Asociado al COVID 19 y a pesar de que se desconoce el riesgo que el mismo puede representar para quienes tienen $\mathrm{VIH}$, existe una gran preocupación por esa población, en tanto de entre ellas, casi dos millones y medio, no toman regularmente medicamentos antirretrovirales para controlar su condición, lo que los vuelve, por supuesto, más vulnerables (Harvie, 2020). El país cerró rápidamente el ingreso de personas provenientes de países considerados de riesgo, cerró también las escuelas e instaló centros de testeo en la capital (Beaubien,2020).

Finalmente, Sudán confirmó 2 casos (Khartoum/Reuters, 2020); Togo 18; Túnez 60 y 3 muertes; Uganda 9; Zambia 3 y en Zimbabwe, se anunciaron ya 2 casos, que incluyen 1 muerte (Zororo Makamba, periodista) (RFI, 2020; WHO, 2020; Al-Thabiti, 2020).

\section{A modo de cierre}

Mientras los 3 países más afectados hasta el momento son Sudáfrica, Egipto y Argelia y el continente cuenta con la dura experiencia y aprendizaje de la difusión del ébola, los distintos gobiernos del continente africano toman con premura medidas de contención del coronavirus, ante el miedo de que sus frágiles sistemas de salud, que enfrentan numerosos desafíos -como el de otras enfermedades- (Heiby, 2014; Fenollar y Mediannikov, 2018), no puedan resistir el embate de una difusión masiva del virus, exacerbada por la pobreza. 
La pandemia ha provocado las ya conocidas restricciones de viaje aéreo, confinamiento social, toques de queda y movilización de fuerzas de seguridad, distintas medidas económicas específicas y la cancelación de diferentes eventos, como conferencias de alto nivel en todo el continente (Uganda pospuso la Cumbre del G77 y el China Summit, previsto para mediados de abril en la capital del país, Kampala y se suspendió también la reunión del Consejo de Paz y Seguridad de la Unión Africana) (Busari y Adebayo, 2020; Getachew, 2020).

La dinámica internacional continúa desplegándose con potencia en este escenario. A la dinámica regional evidenciada, por ejemplo, en el acuerdo de la IGAD (Autoridad Intergubernamental sobre el Desarrollo, bloque económico y comercial de África Oriental, formado por Eritrea, Etiopía, Kenia, Somalia, Sudán, Sudán del Sur, Uganda y Yibuti) de dar una respuesta coordinada a la pandemia (Europa Press, 2020), se suma el accionar de China, que hace sentir su proyección de liderazgo global, a través del envío de ayuda al continente. Así, el 22 de marzo, los Centros para el Control y la Prevención de Enfermedades de África y el Gobierno de Etiopía recibieron un envío de equipos médicos, en el marco de una iniciativa de ayuda lanzada por el Primer Ministro de Etiopía, Abiy Ahmed y las Fundaciones Jack Ma y Alibaba, como parte de las acciones de la estrategia continental africana conjunta para enfrentar esta pandemia, dirigida por la Unión Africana, a través de los mencionados Centros (African Union, 2020). Por otro lado, como ya se mencionó, en otro ejemplo visible del tema, Angola se dispone a recibir colaboración médica de Cuba, con el que firmó su primer acuerdo de colaboración en 1976 y que ha jugado un importante rol en su desarrollo y transformación (Hatzky, 2015; ANGOP, 2019).

\section{Referencias}

African Union (22 de marzo de 2020). Jack Ma and Alibaba Foundations Donate COVID-19 Medical Equipment to African Union Member States. African Union. https://africacdc.org/news/jack-ma-and-alibaba-foundations-donate-covid-19medical-equipment-to-african-union-member-states/

Al-Thabiti, A. (22 de marzo de 2020). Tunisia's death toll from coronavirus rises to 3. Anadolu Agency. https://www.aa.com.tr/en/africa/tunisias-death-toll-fromcoronavirus-rises-to-3/1774807

ANGOP (Agencia Angola Press) (17 de diciembre de 2019). Angola and Cuba to expand bilateral cooperation. ANGOP. http://www.angop.ao/angola/en_us/noticias/politica/2019/11/51/Angola-and- 
Cuba-expand-bilateral-cooperation, a1 bd29b9-524b-4f15-9006-

816da7399545.html

ANGOP (Agencia Angola Press) (24 de marzo de 2020). COVID-19: Síntesis Nacional. ANGOP (24 de marzo). https://m.portalangop.co.ao/angola/es_es/noticias/saude/2020/2/13/COVIDSintesis-Nacional,97404fe1-35ba-4251-b0a2-169889103233.html

Beaubien, J. (21 de marzo de 2020). African Countries Respond Quickly to Spread of COVID-19. NPR.

https://www.npr.org/sections/goatsandsoda/2020/03/21/818894991/africancountries-respond-quickly-to-spread-of-covid-19

Busari, S. y Adebayo, B. (12 de marzo de 2020). Here are the African countries with confirmed coronavirus cases. CNN. https://edition.cnn.com/2020/03/09/africa/nigeria-coronavirus-casesintl/index.html

Europa Press (25 de marzo de 2020). Los países de la IGAD acuerdan coordinar su respuesta a la pandemia de coronavirus. Europa Press. https://www.europapress.es/internacional/noticia-paises-igad-acuerdancoordinar-respuesta-pandemia-coronavirus-20200325220246.html

Fenollar, F. y Mediannikov, O. (2018). Emerging infectious diseases in Africa in the 21st century. New Microbes New Infect, 26, S10-S18. https://www.ncbi.nlm.nih.gov/pmc/articles/PMC6205565/

Getachew, A. (12 de marzo de 2020). Any African Union Commission meeting of 15 people or above will not be held, a meeting facilitator tells Anadolu Agency. Anadolu Agency. https://www.aa.com.tr/en/africa/pan-african-body-cancels-meeting-overcoronavirus-fears/1763751

Harvie, A. (24 de marzo de 2020). COVID-19 pandemic: In a nation of extreme inequality, South Africa's poorest are most at risk. Atlantic Council. https://www.atlanticcouncil.org/blogs/africasource/covid-19-pandemic-in-a-nationof-extreme-inequality-south-africas-poorest-are-most-at-risk/

Hatzky, C. (2015). Cubans in Angola: South-South Cooperation and Transfer of Knowledge, 1976-1991. Madison: University of Wisconsin Press.

Heiby, J. (2014). The use of modern quality improvement approaches to strengthen African health systems: a 5-year agenda. International Journal of Quality in Health Care, 26(2), 117-123. 
Malaymail (24 de marzo de 2020). British tourist dies in Cape Verde after contracting Covid19. Malaymail. https://www.malaymail.com/news/world/2020/03/24/british-touristdies-in-cape-verde-after-contracting-covid-19/1849850

Mednick, S. y Anna, C. (21 de marzo de 2020). Africa Records More Than 1,000 COVID-19 Cases, Spanning at Least 40 Countries. Time. https://time.com/5807731/africacoronavirus-cases-rise/

Khartoum (Reuters) (20 de marzo de 2020). Sudan Confirms Second Coronavirus Case, Khartoum Bans Mass Gatherings. Sudan Confirms Second Coronavirus Case, Khartoum Bans Mass Gatherings. Us News.

https://www.usnews.com/news/world/articles/2020-03-20/sudan-confirmssecond-coronavirus-case-khartoum-bans-mass-gatherings

RFI (2020). First coronavirus deaths in Nigeria and Zimbabwe as Covid-19 grips Africa. RFI (23 de marzo). Recuperado de http://www.rfi.fr/en/africa/20200323-firstcoronavirus-deaths-in-nigeria-and-zimbabwe-as-covid-19-grips-africa

WHO (2020). Coronavirus (COVID-19). WHO Africa Dashboard. Cumulated confirmed cases/Recovered and Deaths. Recuperado de https://www.afro.who.int/healthtopics/coronavirus-covid-19

Wahba, A. L. y Magdy, M. (24 de marzo de 2020). Egypt Imposes Nighttime Curfew to Contain Coronavirus Outbreak. Bloomberg. https://www.bloomberg.com/news/articles/2020-03-24/egypt-imposes-nighttimecurfew-to-contain-coronavirus-outbreak

Xinhua (24 de marzo de 2020). Malaria treatment protocol approved for COVID-19 in Algeria as infections hit 230. China.org.cn. http://www.china.org.cn/china/Off_the_Wire/2020-03/24/content_75850870.htm 